\title{
Environmental and vegetation variables have a greater influence than habitat fragmentation in structuring lizard communities in remnant urban bushland
}

\author{
S. JELLINEK^, D. A. DRISCOLL AND J. B. KIRKPATRICK \\ School of Geography and Environmental Studies, University of Tasmania, Hobart, Tasmania, Australia
}

\begin{abstract}
The expansion of urban areas and adjacent farming land into natural landscapes modifies habitats and produces small isolated pockets of native vegetation. This fragmentation of the natural habitat subdivides animal communities, reduces population sizes and increases vulnerability to extinction. In this paper we investigate whether fragmentation decreases lizard species richness, composition, overall abundance and abundance at the species level. Urban remnants consisting of five small ( $<10 \mathrm{ha}$ ) and four large ( $>10 \mathrm{ha}$ ) fragments of natural bushland were paired with continuous bushland areas located near Hobart, Tasmania, Australia. These remnants were surveyed six times, using pitfall traps, from November 2001 to March 2002. Lizard species richness and abundance were not significantly influenced by habitat fragmentation or fragment size. Egernia whitii was the only lizard species significantly influenced by fragment size, and was only present in large fragments and continuous bush. Vegetation type and structure as well as environmental variables (geology and aspect) influenced the structure of reptile communities. Lizard species that were able to use a number of different habitat types were found to persist at most sites, irrespective of fragment size. Edge environment did not significantly influence lizard species richness or abundance in remnant areas. Lizard species richness was significantly lower in sites that had a high ratio of exotic to native plant species. Therefore, if remnants continue to be invaded by exotic plants, lizard species that require native plant communities will become increasingly vulnerable to local extinction. Our results suggest that lizard species requiring specialized habitats, such as E. whitii, may persist in large urban remnants rather than small urban remnants because large reserves are more likely to encompass rare habitats, such as rocky outcrops. Habitat heterogeneity, rather than size, may be the key to their persistence.
\end{abstract}

Key words: abundance, edge effect, fragment size, lizard, species richness, urban remnants, vegetation.

\section{INTRODUCTION}

Habitat fragmentation is the process of habitat modification or habitat loss that leaves behind small, isolated native vegetation pockets in a landscape of agricultural, urban or otherwise disturbed land (Wilcox \& Murphy 1985; Burkey 1995). The process of vegetation clearing is not random and usually occurs on the most productive land, often leaving remnants relatively unsuitable for other uses (Burgman \& Lindenmayer 1998). The process of fragmentation implies an overall loss of habitat, diminished remnant size, increased distance between remnant areas and increased edge environments (Flather \& Bevers 2002). This in turn has a negative impact on animal and plant communities by subdividing populations, thereby reducing population sizes and increasing vulnerability to extinction (Collinge 1996; Kellman 1996).

*Corresponding author. Present address: RMB 1425, Tallangatta, Victoria 3700, Australia.

Email: sacha_jellinek@hotmail.com.

Accepted for publication September 2003.
Habitat fragments have been compared to oceanic islands because species richness on islands is influenced by remnant area and isolation, and by the processes of immigration and extinction (Kitchener \& How 1982). The size of a fragment and its isolation from other natural areas has a strong influence on the ecological processes occurring within that area, including impacts on population size, community composition, immigration and emigration (Collinge 1996). Isolation refers to the distance of one fragment from another, or of one fragment from continuous bushland (Beier \& Noss 1998). As isolation increases, there is a greater threat of species extinction, both locally and regionally, because the chances of immigration and re-colonization are diminished (Hanski \& Simberloff 1996).

Edge environments can also alter plant and animal communities and ecological processes (Turner 1996; Laurance 2000). The edge environment is the part of a remnant that is influenced by the surrounding cleared or modified land and increases in proportion as fragment size decreases (Turner 1996). Habitat edges are subject to more extreme abiotic conditions than core areas, such as high winds and temperature extremes (Debinski \& Holt 2000). Edges tend to be drier 
(Laurance 2000), more variable in temperature (Debinski \& Holt 2000), have lower humidity (Collinge 1996) and higher rates of windthrow (Turner 1996) than remnant interiors. Micro-environmental changes may permeate remnants for tens of metres (Collinge 1996), or possibly much further (Bolger et al. 1997).

While fragment size, isolation and edge environment may have a direct effect on the abundance and diversity of some animal species, environmental and vegetation variables may also play an important role in structuring animal communities in fragments, because many species require specific microhabitats to survive and reproduce (How \& Dell 2000; Brown 2001). For example, Kitchener et al. (1980) found that the number of plant communities in reserves explained $75 \%$ of the variation in lizard species richness. Hadden and Westbrooke (1996) found that reptile species richness in fragments of native vegetation was significantly positively correlated with habitat variables such as shrub cover and significantly negatively correlated with weed cover. Variables which may have an impact on lizard species richness and abundance include geology and soil type (How \& Dell 2000), vegetation type (Smith et al. 1996), vegetation structure (Hadden \& Westbrook 1996), rainfall (Redburn 1999), rock cover (MacNally \& Brown 2001), litter cover (Melville \& Swain 1999), fire history (Taylor \& Fox 2001) and aspect.

Reptiles represent an important element in forest ecosystems and may be threatened by habitat fragmentation. Reptiles are secondary consumers of small species and prey items for larger predators such as mammals and birds (Brown \& Nelson 1993). Dickman (1987) and Burkey (1995) found that lizards were one of the few vertebrate groups that persisted on a number of smaller habitat fragments or islands at least as well as on a single large island or patch of habitat. More recent research shows, however, that many reptiles are vulnerable to decline after habitat loss and fragmentation (Sarre 1995; Smith et al. 1996; Driscoll 2004). For example, in a fragmented farming landscape with about $10 \%$ native vegetation cover, Driscoll (2004) suggested that two reptile species had become extinct and five others were declining.

In Australia and elsewhere in the world there has been a rapid expansion of urban areas and adjacent farming land into previously undisturbed landscapes, modifying natural ecosystems and altering or depleting native vegetation (Kellman 1996; How \& Dell 2000). Urbanization and the expansion of agriculture generally creates a mosaic of habitat patches of different shapes and sizes and, through time, the continual disturbance by humans and invasions of exotic species modify the flora and fauna within those areas (Dickman 1987).

Although the processes of habitat fragmentation have been similar between urbanized and agricultural land, resulting in similar consequences for faunal populations (Dickman 1987; How 1998), there are some fundamental processes that differ between the two environments, which may influence faunal communities in different ways. In the urban environment, roads, buildings and fences represent physical fragmentation and also create a physical barrier between patches, which impede or redirect animal movement (Soule et al. 1992). Urban constructions create ecotones, act as a source of pollution, and they are filters (restricting some species), barriers (stopping movement) and population sinks (road mortalities) (Knight et al. 1995; Theobald et al. 1996). Urban constructions may also act as corridors, increasing the spread of diseases, aiding the dispersal of exotic species (e.g. from dumped garden refuse) (Theobald et al. 1996), altering predator-prey dynamics (i.e. subsidized predators) (Schneider 2001) and increasing human access to natural areas (Dickman 1987). Habitats are likely to become more degraded and homogeneous in urban fragments and the literature suggests that loss of habitat structure can reduce reptile species richness (Brown 2001). Thus, reptile species in urban fragments potentially suffer a greater range of detrimental impacts than those in rural fragments of equivalent size if they require specific microhabitats (Soule et al. 1992).

The present study has three aims. First, to determine if urban fragments in Hobart, Tasmania, Australia, have different lizard species richness, composition, overall abundance and abundance at the species level in comparison to continuous bushland areas. We expect that: (i) lizard species richness and abundance will be lower in fragments than in continuous bush; and (ii) lizard species richness will decrease as fragment size decreases. Second, to determine whether edge environments affect lizard species richness, composition, overall abundance and abundance at the species level. We expect that: (iii) there will be a significant edge effect on reptile species. Third, to determine if abiotic and biotic influences on lizard species richness and abundances are related to habitat characteristics. We expect that: (iv) variables related to plant communities as well as environmental variables will have a significant influence on the reptile fauna.

\section{METHODS}

Pitfall trapping over a 5-month period (November 2001 to March 2002) was used to determine lizard species richness and abundance in nine remnant bushland sites located in Hobart (Fig. 1). Tasmania experiences a temperate maritime climate. The mean annual temperature for Hobart is $16.8^{\circ} \mathrm{C}$, with a mean daily maximum temperature of $23.1^{\circ} \mathrm{C}$ in January

We sampled five small $(<10 \mathrm{ha})$ and four large ( $>10$ ha) sites. Each site was paired with a control site 
located in continuous bushland that had similar site variables including geology, vegetation type and structure, aspect, slope and fire history (Table 1). All continuous habitats were at least $3 \mathrm{~km}$ from each other, whilst the closest remnants (Rosny Hill and Rosny Point) were approximately $300 \mathrm{~m}$ from each other and separated by urban development (Fig. 1).

Each site was sampled using one pit-grid covering a $45 \mathrm{~m} \times 15 \mathrm{~m}$ area containing 10 pitfall traps. To enable the detection of edge effects two lines of five pitfall traps spaced at $10 \mathrm{~m}$ intervals were positioned perpendicular to the edge, beginning $15 \mathrm{~m}$ from the edge and extending $60 \mathrm{~m}$ into the remnant. Fence arrays alternated at 90 degrees, forming a criss-cross pattern. The arrangement of pitfall traps was the same in the interior of continuous native bush.

Each trap configuration contained one tin, $150 \mathrm{~mm}$ wide $\times 180 \mathrm{~mm}$ deep, which was dug into the ground so that the rim sat flush with the top of the soil. Each tin had small drainage holes in the bottom to allow water to escape during wet weather. Leaf litter and other debris were placed in the bottom of each trap to provide animals with shelter from heat exposure and potential predators. To reduce attacks by ants, the rims of traps were sprayed with surface insecticide. Drift fences $5 \mathrm{~m}$ long and $30 \mathrm{~cm}$ high were made from $200 \mu \mathrm{m}$ black polyurethane plastic and used in con- junction with pitfall traps. Fences were placed directly over the centre of traps and buried approximately $2 \mathrm{~cm}$ into the ground.

Each site was surveyed continuously for six days (one day regarded as a 24-h period) on six occasions: once each in November and December 2001, twice in January 2002 and once each in February and March 2002. For each reptile in each survey site, the species and trap location were recorded. Reptiles were individually toe-clipped and released. Recaptured individuals were not included in abundance counts. Abundance was calculated from total captures.

Surveys of the vegetation were conducted within the trapping quadrat at every site. The variables recorded were: percentage cover of the tallest stratum; second tallest stratum; ground stratum; rock; fallen wood; bare ground; tussock grass; herbs; shrubs; litter; and exotic plants. Cover was estimated using the following system: $1=0-5 \%, 2=5-25 \%, 3=25-50 \%, 4=50-$ $75 \%, 5=75-95 \%$ and $6=95-100 \%$ (O'Shea \& Kirkpatrick 2000). These classes were aggregated into low $=0-25 \%$, medium $=25-75 \%$, and high $=75-$ $100 \%$ cover categories for Analysis of Variance. The Bitterlich variable radius method (Mueller-Dombois \& Ellenberg 1974) was used to estimate the basal area of tree species. All of the vascular plant species that were observable within the trapping grid were recorded.

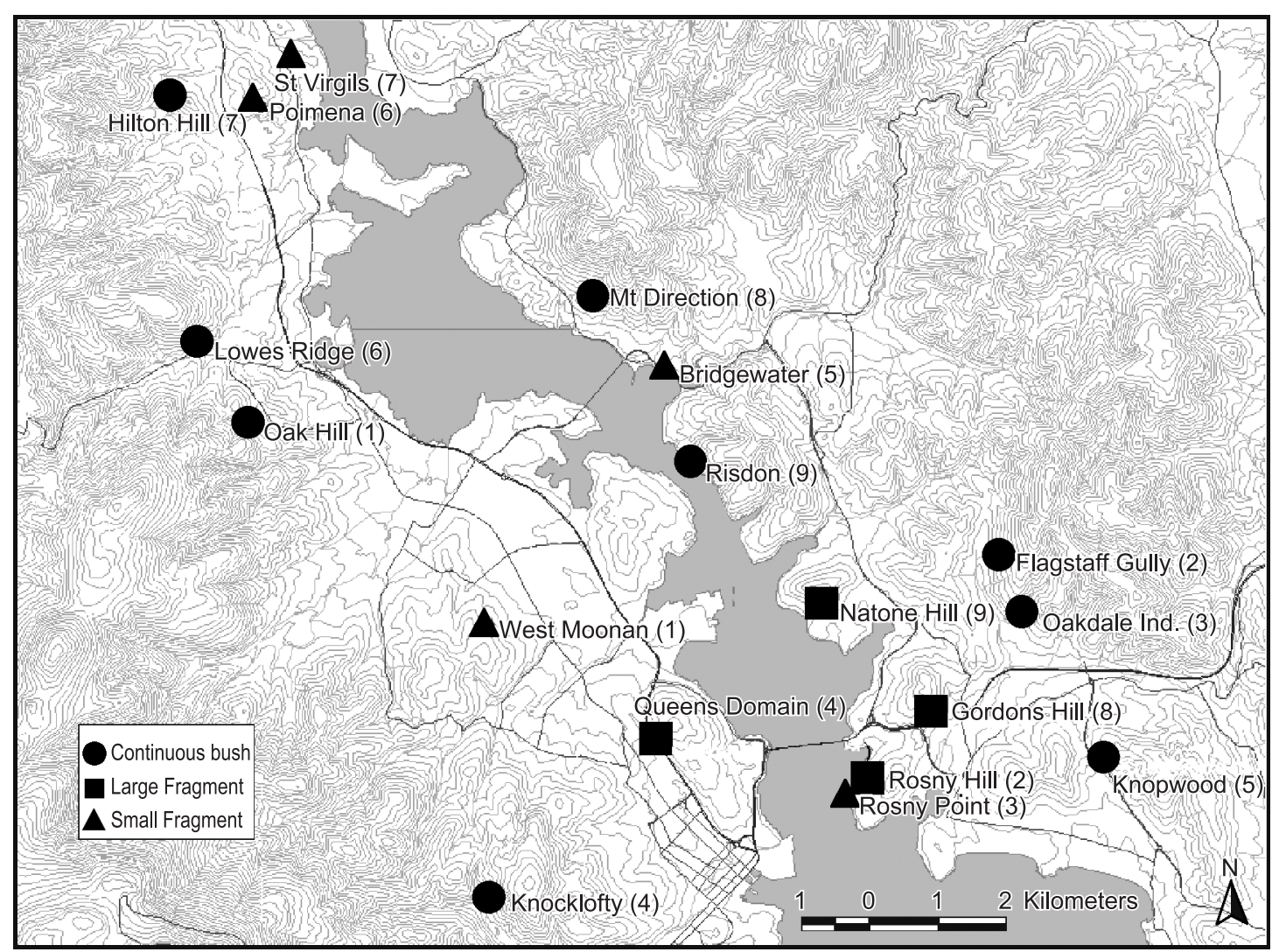

Fig. 1. Study site locations in Hobart, Tasmania, Australia, depicting continuous bushland areas, large and small remnants with site pairs (1-9): $\bullet$, continuous bush; $\mathbf{\square}$, large fragment; $\boldsymbol{\Lambda}$, small fragment. 
A ratio of exotic plant species richness to native plant species richness was calculated. Geology (sandstone or dolerite), aspect, slope, solar radiation and rainfall were determined for each site. Geology was determined from geological survey maps of Hobart (Leaman 1972; Clarke \& Forsyth 2000). Aspect and slope were measured using a compass and a clinometer, respectively. Aspect was divided into five categories: south-east (1); east or south (2); north-east or south-west (3); north or west (4); and north-west (5) (O'Shea \& Kirkpatrick 2000). Solar radiation was calculated using aspect and slope data for each site in summer (Nunez 1983). Rainfall was downloaded from the Australian Bureau of Meteorology website after each day of trapping.

\section{Analysis}

A generalized linear mixed model (GLMM) with a Poisson distribution and a natural logarithm link function was used to test for an effect of habitat fragmentation on lizard species richness and abundance (Nicholls 1989). The model used included the random effect of pair, taking into account the variation due to pairs of sites. The fixed effect, fragmentation, was then fitted, to test for differences between continuous bush, large ( $>10 \mathrm{ha}$ ) and small ( $<10 \mathrm{ha}$ ) fragments. The variables used included overall lizard species richness and abundance, calculated by grouping lizard species by site, as well as individual abundance of Niveoscincus metallicus (metallic skink), Bassiana duperreyi (three-lined skink), Pseudemoia entrecasteauxii (southern grass skink) and Egernia whitii (White's skink). Other species were not analysed individually because they were rarely captured. There were two degrees of freedom for fragmentation and eight degrees of freedom for the effect of pair.

To test for an effect of edge, reptile captures were recorded for each pitfall trap in remnant areas. Linear regression and quadratic regression analyses tested for the relationship between the dependent variables, lizard species richness and abundance, and distance from edge.

Lizard and vegetation community data were entered into DECODA (Minchin 1990) and each data set was ordinated using non-metric multidimensional scaling

Table 1. Paired remnant and continuous sites located in the Hobart region, Tasmania, Australia

\begin{tabular}{|c|c|c|c|c|c|c|}
\hline Pair & Site & Abbreviation & Size & Easting & Northing & Dominant Vegetation \\
\hline \multirow[t]{2}{*}{1} & West Moonah & WM & Small (2.8 ha) & 523313 & 5255688 & Eucalyptus viminalis \\
\hline & Oak Hill & $\mathrm{OH}$ & Continuous & 519915 & 5258570 & E.pulchella \\
\hline \multirow[t]{2}{*}{2} & Rosny Hill & $\mathrm{RH}$ & Large (14 ha) & 528989 & 5253489 & Allocasuarina verticillata \\
\hline & Flagstaff Gully & FG & Continuous & 530827 & 5256694 & A. verticillata \\
\hline \multirow[t]{2}{*}{3} & Rosny Point & $\mathrm{RP}$ & Small (8.7 ha) & 528585 & 5253166 & A. verticillata \\
\hline & Oakdale & OI & Continuous & 531193 & 5255801 & A. verticillata \\
\hline \multirow[t]{2}{*}{4} & Queens Domain & QD & Large (18 ha) & 525835 & 5253938 & E. pulchella \\
\hline & Knocklofty & KR & Continuous & 523438 & 5251601 & E.pulchella \\
\hline \multirow[t]{2}{*}{5} & Bridgewater & BW & Small (0.7 ha) & 525927 & 5259378 & E. globulus \\
\hline & Knopwood & $\mathrm{KH}$ & Continuous & 532371 & 5253702 & E.globulus \\
\hline \multirow[t]{2}{*}{6} & Poimena & PR & Small (4.8 ha) & 519992 & 5263244 & A. verticillata \\
\hline & Lowes Ridge & LR & Continuous & 519160 & 5259746 & A. verticillata \\
\hline \multirow[t]{2}{*}{7} & St Virgils & SV & Small (0.5 ha) & 520426 & 5263934 & A. verticillata \\
\hline & Hilton Hill & $\mathrm{HH}$ & Continuous & 518672 & 5263261 & A. verticillata \\
\hline \multirow[t]{2}{*}{8} & Gordons Hill & $\mathrm{GH}$ & Large (47 ha) & 529818 & 5254375 & E.globulus \\
\hline & Mt Direction & MD & Continuous & 524845 & 5260476 & E. viminalis \\
\hline \multirow[t]{2}{*}{9} & Natone Hill & $\mathrm{NH}$ & Large (41 ha) & 528276 & 5255921 & E. amygdalina \\
\hline & Risdon & RR & Continuous & 526343 & 5257987 & E. amygdalina \\
\hline
\end{tabular}

Pair number corresponds with Fig. 1.

Table 2. Mean abundance (with $95 \%$ confidence limits) for four lizard species, total lizard abundance and number of lizard species in small fragments, large fragments and continuous bushland

\begin{tabular}{|c|c|c|c|c|c|c|c|c|}
\hline \multirow[b]{2}{*}{ Bassiana duperreyi } & \multicolumn{2}{|c|}{ Small } & \multicolumn{2}{|r|}{ Large } & \multicolumn{2}{|c|}{ Continuous } & \multirow{2}{*}{$\begin{array}{c}\text { Dev/Rdev } \\
0.70 / 1.63\end{array}$} & \multirow{2}{*}{$\begin{array}{c}P \\
0.67\end{array}$} \\
\hline & 3.80 & $(2.12-6.83)$ & 4.25 & $(2.29-7.9)$ & 3.11 & $(1.92-5.04)$ & & \\
\hline Egernia whitii & 0.00 & & 2.25 & $(1.08-4.69)$ & 2.78 & $(1.79-4.32)$ & $16.8 / 1.21$ & 0.004 \\
\hline Niveoscincus metallicus & 32.2 & $(21.2-49.0)$ & 34.3 & $(21.8-53.9)$ & 36.9 & $(27.7-49.4)$ & $7.47 / 7.06$ & 0.40 \\
\hline Pseudemoia entrecasteauxii & 9.40 & $(4.11-21.5)$ & 9.50 & $(3.78-23.9)$ & 3.22 & $(1.12-9.25)$ & $15.68 / 8.07$ & 0.21 \\
\hline Lizard Abundance & 45.4 & $(32.9-62.7)$ & 50.3 & $(35.7-70.7)$ & 46.0 & $(36.2-58.4)$ & $8.30 / 5.74$ & 0.30 \\
\hline Lizard Species & 2.60 & $(1.49-4.53)$ & 3.75 & $(2.24-6.29)$ & 3.67 & $(2.59-5.19)$ & $0.58 / 0.24$ & 0.56 \\
\hline
\end{tabular}

Dev/Rdev, mean deviance of factor tested/residual mean deviance. 
(a)

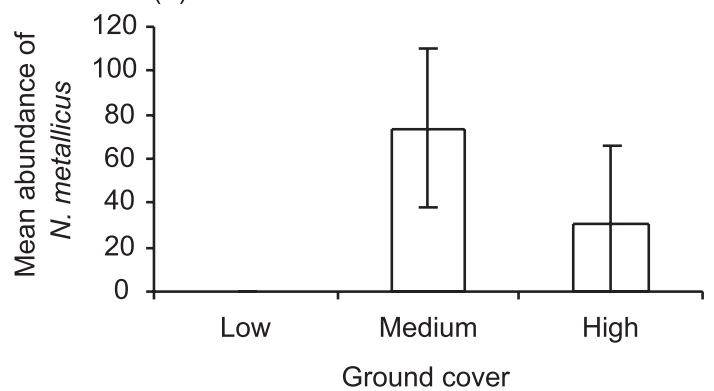

(c)

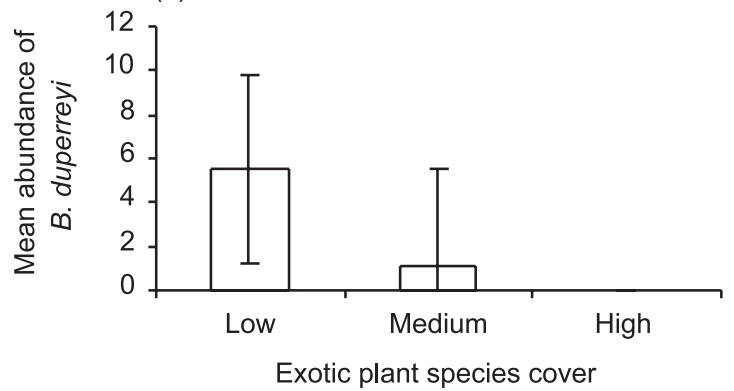

(b)

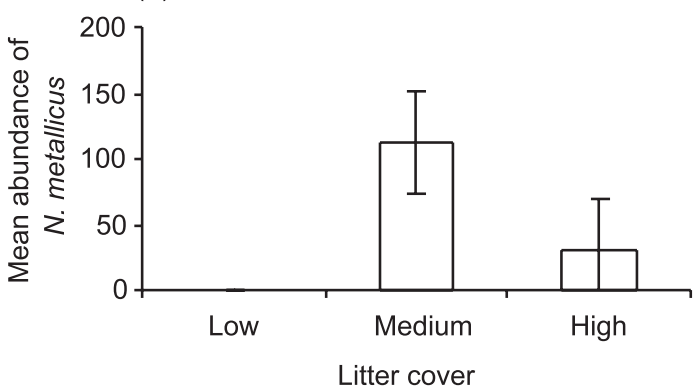

(d)

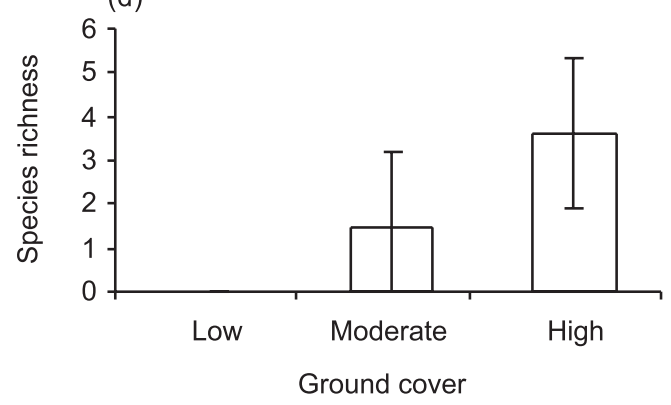

Fig. 2. Four significant relationships were observed between plant categorical variables and lizard variables: (a) mean abundance of Niveoscincus metallicus in study sites with moderate to high ground cover; (b) mean abundance of N. metallicus in study sites with moderate to high litter cover; (c) mean abundance of Bassiana duperreyi in sites with low to moderate exotic plant species cover; and (d) lizard species richness in study sites with moderate to high ground cover. Error bars are $95 \%$ confidence intervals.

(MDS). MDS is a robust non-linear ordination technique that minimizes the discrepancy between the rank order of sample dissimilarities and ordination distance (Minchin 1987; Wahren et al. 1999). The Bray-Curtis coefficient was used to describe the dissimilarity between pairs of sites. For each ordination, the relationship between reptile community composition, or vegetation and environmental variables and the ordination pattern were examined using vectors. Vector fitting is a procedure that determines the direction and correlation of the independent variables with the ordination scores (Minchin 1987; Wahren et al. 1999).

An examination of the stress values showed that twodimensional axes were sufficient to achieve low levels of stress for both lizard (stress value $=0.136$ ) and vegetation (stress value $=0.142$ ) data. The axes labels for lizard community data were MDS1Liz (axis 1) and MDS2Liz (axis 2) while the axes for native vegetation community composition were labelled MDS1Nat (axis 1) and MDS2Nat (axis 2).

To measure explained variation between classes of geology (dolerite and sandstone) and aspect (1-5) against plant and lizard ordination scores, one-way ANOVAs were performed. Linear regression was used to relate continuous environmental variables (slope, rainfall and solar radiation) to plant and lizard ordination scores.
Lizard species richness and abundance as well as individual species abundance were correlated against all environmental and vegetation variables. Correlation analysis establishes the degree of association (positive or negative $r$-value) between pairs of variables in a population sample (Sokal \& Rohlf 1995). Variables that showed a significant correlation to lizard species richness and lizard abundance $(P<0.05)$ were individually analysed with a linear or quadratic regression and a fitted line plot was created. Those vegetation variables that contained class data were analysed with a one-way ANOVA against individual lizard abundance, species richness and overall abundance.

Fig. 3. Linear regression (a, b and e-k) and quadratic regression (c, d) fitted line plots displaying the influence of vegetation variables on Niveoscincus metallicus total captures ( $P$-values: $\mathrm{a}=0.015, \mathrm{~b}=0.017)$, Pseudemoia entrecasteauxii total captures $(\mathrm{c}=0.000, \mathrm{~d}=0.004, \mathrm{e}=0.001)$, Bassiana duperreyi total captures $(\mathrm{f}=0.002)$, lizard species richness ( $\mathrm{g}=0.039)$, multi dimensional scaling axis 1 for lizard community composition (MDS1Liz) $(\mathrm{h}=0.001, \mathrm{i}=0.048)$ and multi dimensional scaling axis 2 for lizard community composition (MDS2Liz) $(j=0.031, \mathrm{k}=0.028)$. 

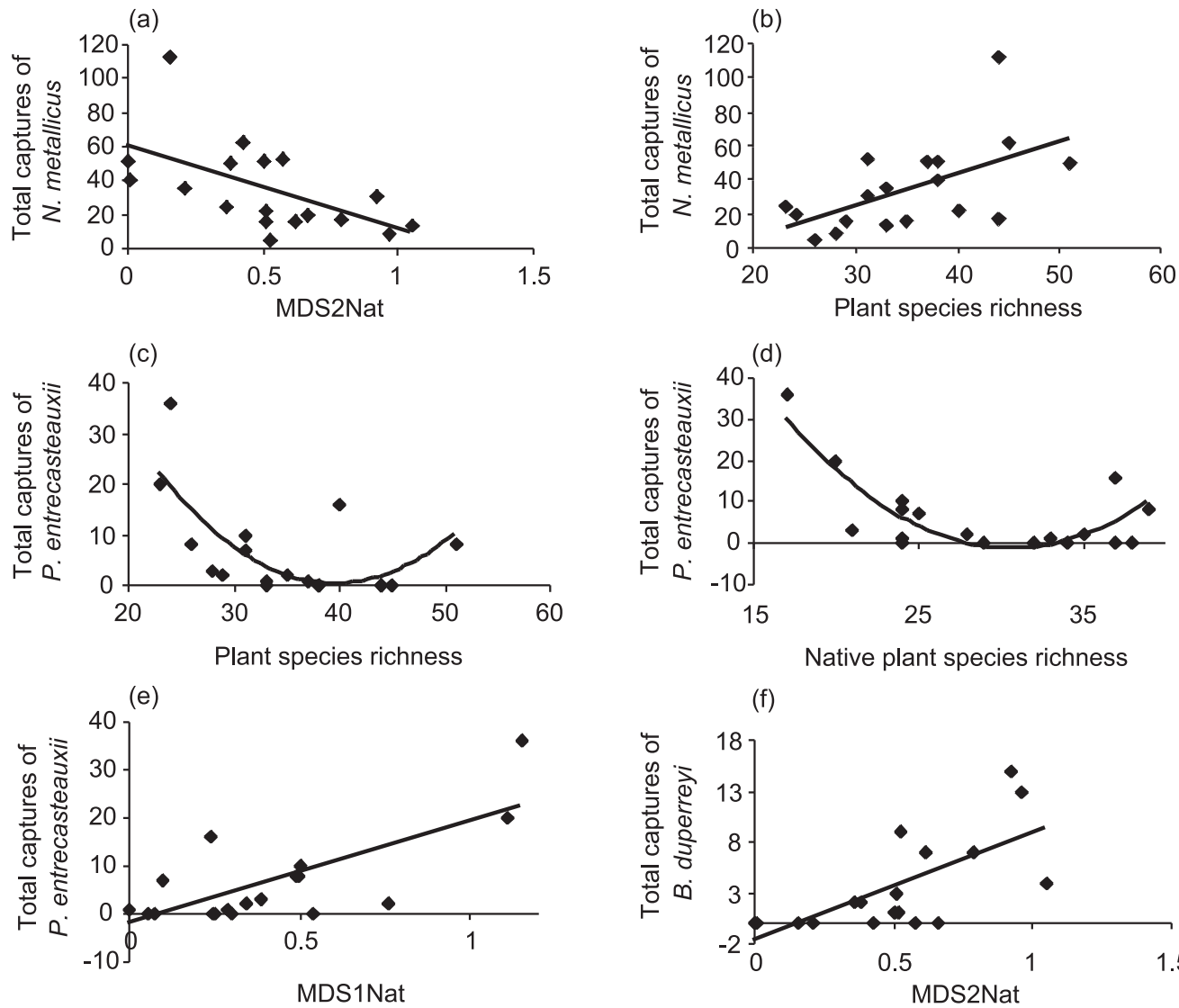

(f)
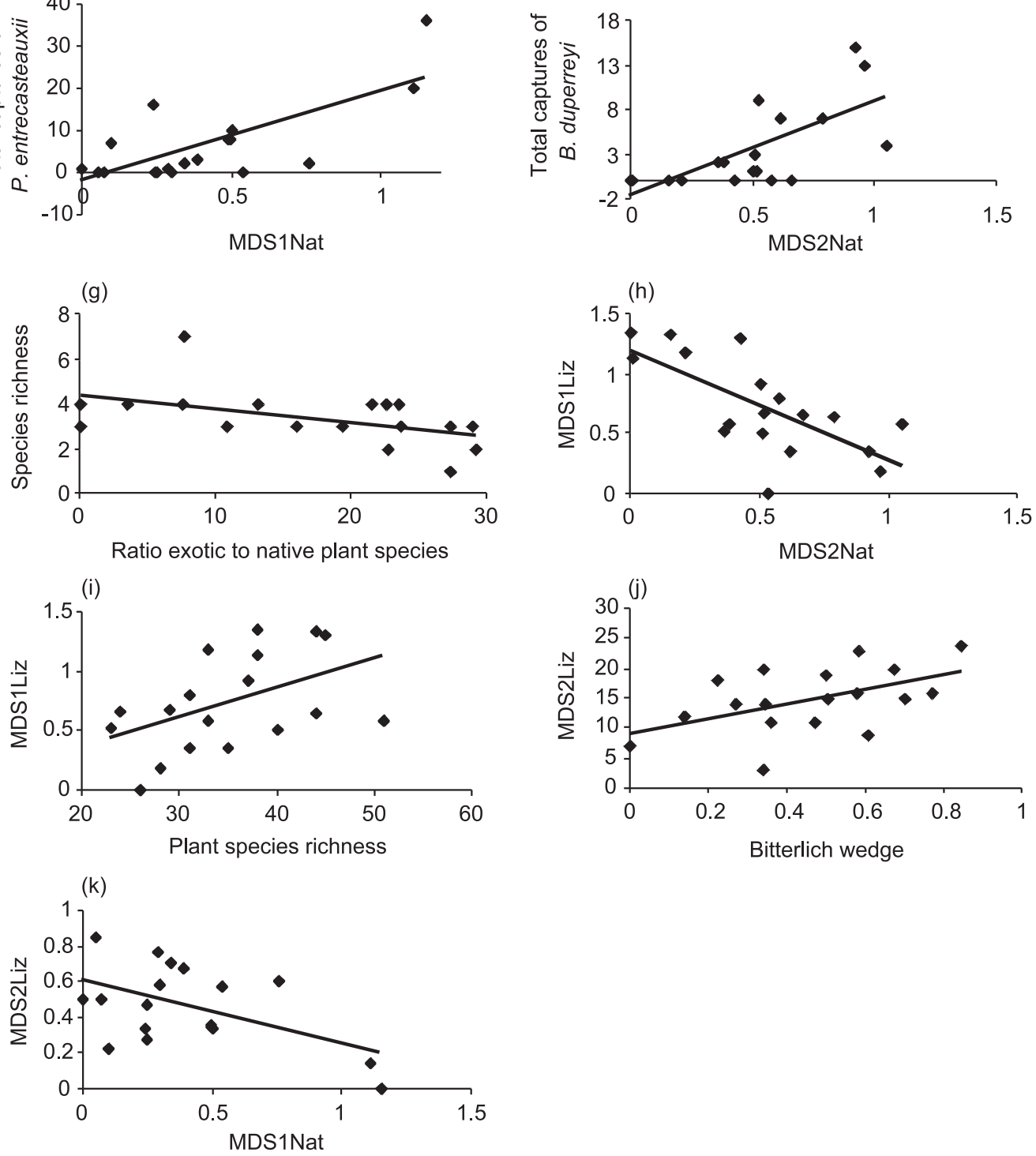


\section{RESULTS}

\section{Habitat fragmentation}

Only Egernia whitii showed a significant response to fragment size and was only captured in large remnants and continuous bush (Table 2). The three other species with relatively high abundance, Niveoscincus metallicus, Bassiana duperreyi and Pseudemoia entrecasteauxii, did not show a significant response to fragmentation (Table 2). Total lizard abundance and number of lizard species also did not differ significantly among remnant classes. Six other species were captured in the study: Lampropholis delicata (number captured 3, site code $\mathrm{WM}, 1 \mathrm{OH}, 2 \mathrm{KR}, 1 \mathrm{PR}, 1 \mathrm{HH})$; Tiliqua nigrolutea (2 RH, 1 PR, 2 NH); Pseudemoia pagenstecheri (1 KR); Tympanocryptis diemensis $(1 \mathrm{OH})$; Niveoscincus ocellatus (1 OH); N.pretiosus (1 LR). The latter four species were only captured at continuous sites. Niveoscincus metallicus was the only species recorded at all sites.

\section{Edge environment}

There was no significant response to edge environment for total abundance, individual abundance or species richness using either linear regression or quadratic regression analysis. Neither overall abundance nor individual abundance for Niveoscincus metallicus, Pseudemoia entrecasteauxii, Bassiana duperreyi and Egernia whitii increased or decreased significantly as distance from the edge increased at fragmented sites. Species richness did not alter as distance from the edge increased.

\section{Vegetation and environmental variables}

In contrast to the analysis of area, isolation and edge, vegetation variables showed strong correlations with lizard distribution. Niveoscincus metallicus was significantly negatively influenced by ground cover $(P<0.05)$ and litter cover $(P<0.001)$ (Fig. 2a,b). Niveoscincus metallicus also significantly decreased in abundance as the scores on the second MDS axis for native vegetation community composition increased $(P<0.05)$ (Fig. 3a), and became more abundant as plant richness increased $(P<0.05)$ (Fig. 3b). Both of these variables were substantially influenced by high $N$. metallicus abundance at one site and when this site was excluded from the analysis no significant influence was evident. Pseudemoia entrecasteauxii was less abundant at sites that had moderate plant species richness and moderate native plant species richness, but was more abundant either at sites which had very low or very high plant species richness and native plant species richness (Fig. 3c,d). Pseudemoia entrecasteauxii increased in abundance as scores on MDS axis 1 for native vegetation community composition increased $(P<0.001)$ (Fig. 3e). Bassiana duperreyi abundance was strongly positively influenced by MDS axis 2 for native vegetation community composition $(P<0.01)$ (Fig. 3f), but negatively influenced by exotic plant cover $(P<0.05)$ (Fig. 2 c). Pseudemoia entrecasteauxii was most abundant on north-west aspects and Bassiana duperreyi was most abundant on north and west aspects (Fig. 4). MDS axis 2 for native vegetation community composition and MDS axis 2 for lizard community composition were also significantly related to aspect (Fig. 4).

Lizard species richness was significantly positively associated with ground cover $(P<0.05)$ (Fig. 2 d) but significantly negatively associated with the ratio of exotic plant species to native plant species $(P<0.05)$ (Fig. 3g). MDS axis 1 for lizard community composition was strongly negatively related to MDS axis 2 for native vegetation community composition $(P<0.001)$ (Fig. 3h). MDS axis 1 for lizard community composition was also positively related to plant species richness $(P<0.05)$ (Fig. 3i). MDS axis 2 for lizard community composition was positively correlated with tree basal area $(P<0.05)$ (Fig. $3 j)$ and negatively correlated with MDS axis 1 for native vegetation communiy composition $(P<0.05)$ (Fig. $3 \mathrm{k}$ ).

Variation among sites in lizard species composition (Fig. 5a) and floristic community composition (Fig. 5b) are displayed in two two dimensional ordinations. Factors that correlated with the MDS axes for lizard community composition were shrub cover, aspect, MDS axis 1 for native vegetation community composition and MDS axis 2 for native vegetation community composition. Shrub cover and MDS axis 2 for native vegetation community composition had an

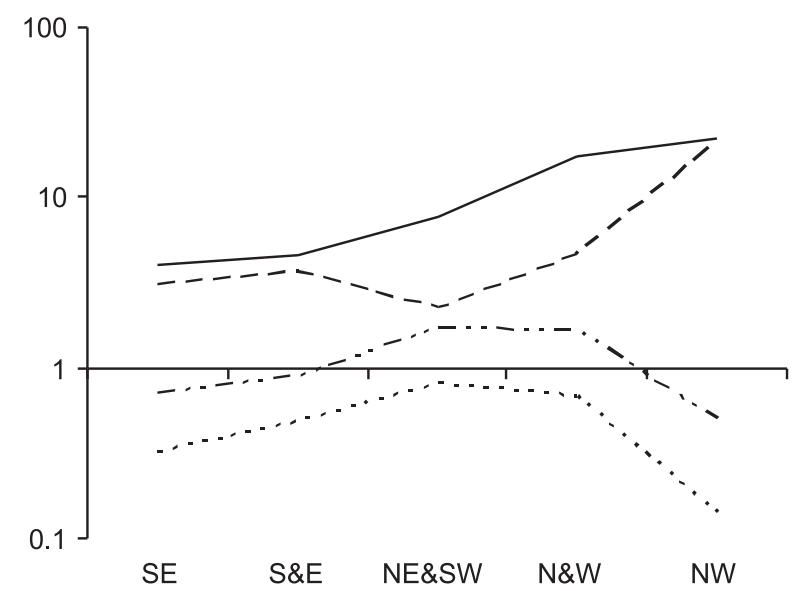

Fig. 4. The influence of aspect on Bassiana duperreyi (-) and Pseudemoia entrecasteauxii (- - ) total captures and on scores for multi dimensional scaling axis 2 for native vegetation community composition (MDS2Nat; - - - ) and MDS axis 2 for lizard community composition (MDS2Liz; - - - -). 
opposite relationship and these were at right angles to MDS axis 1 for native vegetation community composition and aspect. MDS axis 1 for lizard community composition was significantly positively correlated with increasing $N$. metallicus abundance $(R=0.752)$ but negatively correlated with $B$.duperreyi abundance $(R=-0.749)$ (Fig. 5a). MDS axis 2 for lizard community composition was significantly negatively correlated with abundance of P.entrecasteauxii $(R=-0.760)$ (Fig. 5a).

Geology significantly influenced MDS axis 1 for native vegetation community composition $(P=0.001)$. Factors that correlated with the MDS axes for native vegetation community composition were bare ground, Bitterlich Wedge, native plant species richness, MDS axis 1 for lizard community composition, and geology. Geology and bare ground had an opposite relationship that was parallel to MDS axis 1 for lizard community composition (Fig. 5b).

(a)

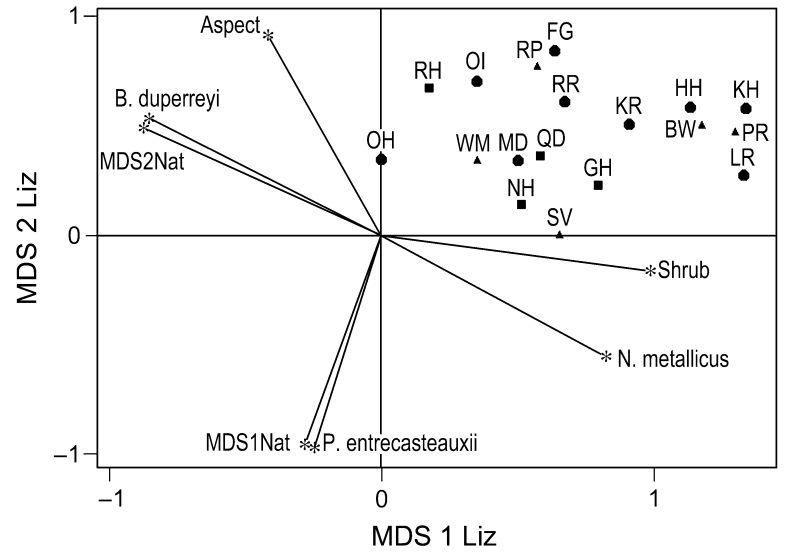

(b)

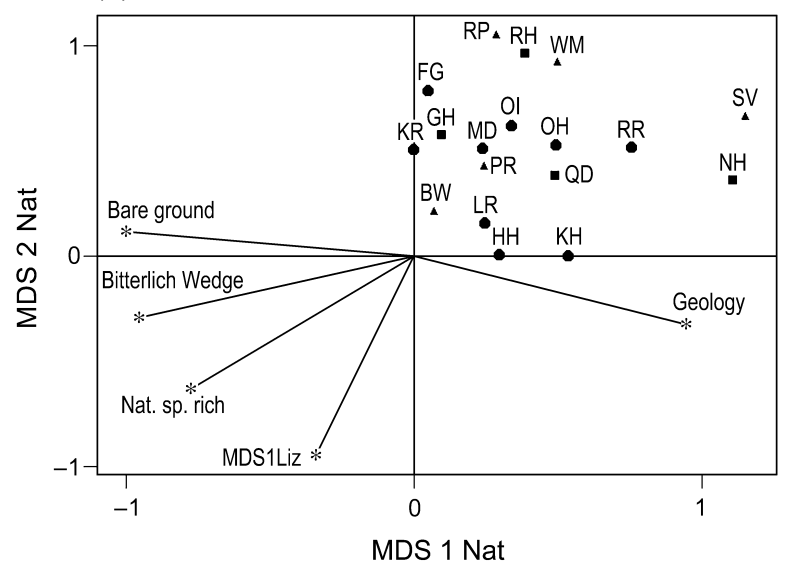

Fig. 5. (a) Environmental and vegetation composition vectors and individual lizard species in lizard community composition ordination space (MDS1Liz and MDS2Liz); and (b) environmental, vegetation and lizard community composition vectors in floristic community ordination space (MDS1Nat and MDS2Nat). Letters correspond to site names; $\bullet$, continuous; $\mathbf{\square}$, large; $\boldsymbol{\Lambda}$, small.

\section{DISCUSSION}

\section{Fragmentation}

Lizard species richness and abundance were not influenced by habitat fragmentation or by fragment size. This is consistent with some other studies (Burkey 1995; MacNally \& Brown 2001). For example, observations by Kitchener et al. (1980) indicated that no large-scale loss of lizard species had occurred in large nature reserves on the Western Australian wheat-belt after long-term (70 years) habitat fragmentation.

Three species commonly caught and observed in both remnants and continuous habitats were N. metallicus, P.entrecasteauxii and B. duperreyi. These species may be viewed as habitat and resource generalists because they are able to persist in a number of different habitats, including remnants and the surrounding urban matrix (Rawlinson 1974; Hutchinson et al. 2001). For example, Smith et al. (1996) found that the lizard fauna remaining in remnant vegetation in the Western Australian wheat-belt was dominated by small species that had low spatial requirements and generalized habitat requirements. Generalist species probably persisted in remnants because they were able to use a number of different resources, forage in urban gardens and along roadside verges (Smith et al. 1996; Melville \& Swain 1999). These factors mean that generalist lizard species have a greater ability to persist in smaller, more degraded remnants than specialist species (Kitchener \& How 1982; MacNally \& Brown 2001).

Another study in the Western Australian wheat-belt, conducted by Kitchener et al. (1980) found that, while most skink species were abundant on small reserves, the genus Egernia was not. The only lizard species significantly influenced by fragment size in Hobart was Egernia whitii. Similarly, MacNally and Brown (2001) did not record $E$. whitii from fragmented habitats in the box-ironbark region of central Victoria, Australia, and they believed that the scattered distribution of this species in continuous bush reflected the limited extent of suitable rocky habitats. Rocky habitats inhabited by E. whitii are probably more likely to persist in urban areas because these areas would be more difficult to develop. In agricultural environments, similar to those surveyed by MacNally and Brown (2001), rocky areas might be modified by grazing (Abensperg-Traun et al. 1996). Thus, although E. whitii exhibits a preference for continuous bushland (MacNally \& Brown 2001; present study), it may be able to persist in fragmented urban landscapes, particularly in large remnants, if suitable rocky habitats are present. Specialized habitats, like rocky outcrops, are more likely to be present in larger fragments, and large remnants may allow rockdwelling Egernia species to disperse between outcrops 
and breed with unrelated mates (MacNally \& Brown 2001; Stow et al. 2001).

\section{Correlations with the environment}

Environmental variables, especially vegetation variables, play an important role in structuring reptile communities (Kitchener et al. 1980; Dickman 1987; Brown \& Nelson 1993). As much as $75 \%$ of the variation observed in lizard species richness between remnants may be accounted for by vegetation associations (Kitchener et al. 1980). This is consistent with the results of the present study. Floristic composition is highly influenced by both geology and aspect in the vicinity of Hobart (Hogg \& Kirkpatrick 1974; Kirkpatrick \& Marks 1985).

The three most abundant and widespread lizard species (P.entrecasteauxii, N. metallicus and B. duperreyi) each displayed a high abundance in a number of different habitat types. Pseudemoia entrecasteauxii preferred plant communities located on sandstone and its abundance was also correlated with moister aspects, which accords with other findings for this species (Redburn 1999). Plant communities on sandstone had a less dense understory and a lower tree basal area than dolerite sites, possibly because soils located on sandstone are poorer in important plant nutrients than those on dolerite (Jackson 1999). Bassiana duperreyi preferred sparsely vegetated plant communities that were associated with dry dolerite slopes with a northerly or westerly facing direction. Niveoscincus metallicus preferred plant communities located on aspects with high soil moisture growing on dolerite. Niveoscincus metallicus also preferred diverse, shrubby plant communities that had a dense understory and a high tree basal area. Melville and Swain (1999) also found that N. metallicus occupied microhabitats closely associated with dense ground-cover vegetation. Densely vegetated environments that have high amounts of ground cover probably provide the diverse array of environments that suit the generalist ecology of N. metallicus (Melville \& Swain 1999; Hutchinson et al. 2001).

Overall, lizards preferred plant communities with high tree basal area. This probably reflects high litter abundance. Brown (2001) also found that abundances of reptile species in box-ironbark forests of southeastern Australia were highly correlated with groundlayer attributes such as litter depth. Smith et al. (1996) noted that the Australian skink species, Tiliqua rugosa, Tiliqua occipitalis, Menetia greyii, Lerista muelleri and Lerista macrophisthopus, were most likely to be found in areas of dense woody litter and shrub cover. A dense woody microhabitat may also act as a place for grounddwelling lizards to bask. Other ground layer attributes are important in structuring lizard communities, as the present study recorded higher lizard species richness at dolerite sites, possibly as a result of increased rock cover. The above results showed that lizard species richness was highly correlated with different plant communities that, in turn, were highly correlated with the environmental variables associated with an area. The decline or persistence of individual reptile species in remnants may be strongly linked to the influence of environmental and vegetation variables rather than to the more commonly investigated effects of remnant size, isolation and edge.

The value of native vegetation for lizard community composition also appears to be important because lizard species richness increased as the ratio of exotic plant species to native plant species decreased. Bassiana duperreyi also had a negative association with exotic plant cover. These results confirm studies by other investigators who found that densities of reptile species were negatively correlated with weed density (Hadden \& Westbrooke 1996; Smith et al. 1996). O'Shea and Kirkpatrick (2000) found that it took 30 years for native vegetation located in urban remnants to be transformed into areas largely dominated by exotic plant species in Hobart, Tasmania. This may have substantial implications for the persistence of reptile species located in urban remnants because lizard community composition may alter in urban remnants as time since isolation increases. These alterations may be dependent on the size of the habitat, and how close urban gardens are from the remnant edge, due to the increased risk of dumped garden refuse and other human related disturbances (Theobald et al. 1996). All of the sites studied had been isolated for more than 30 years, so larger habitats may be the only areas which retain a reasonably high proportion of their native plant species. In the future, however, large areas may become dominated by exotic plant species if weeds are not controlled, diminishing habitat heterogeneity and reducing specialized microhabitats, potentially resulting in localized extinctions.

\section{Edge effects}

Capture rates demonstrated that lizard species were equally dispersed throughout the fragmented landscapes and were not restricted to edge-related niches, such as roadside verges or fragment cores. However, these results may be limited in some respects since an edge effect may extend less than $15 \mathrm{~m}$, the starting point for trap lines in this study, or may exceed the length of the trap grid. In a study of rodents in urban fragments, Bolger et al. (1997) demonstrated that edge effects could penetrate through the whole study area, not just the boundary. In the present study, the edge environment did not influence overall reptile species richness or abundance, therefore differences between continuous and remnant landscapes probably reflect 
area relationships or factors other than edge, unless the whole fragment was influenced by edge effects.

\section{Conclusion}

A variety of environmental and vegetation variables play an important role in structuring lizard community composition at sites around Hobart, while remnant size and edge environment generally do not. However, at least one lizard species, Egernia whitii, was susceptible to fragmentation effects. Although some reptile species appeared to be resilient to habitat fragmentation, individual reptile species may face an increasing risk of local extinction if exotic plant species or other forms of habitat degradation are allowed to expand through urban remnants.

\section{ACKNOWLEDGEMENTS}

The authors thank the Australian Society of Herpetologists and the Royal Zoological Society of New South Wales for providing research funding. The Tasmanian Parks and Wildlife Service (FA01237) and the University of Tasmania Animal Ethics Committee (A0006315) provided approval for this project.

\section{REFERENCES}

Abensperg-Traun M., Smith G. T., Arnold G. W., Steven D. E. (1996) The effects of habitat fragmentation and livestock grazing on animal communities in remnants of gimlet Eucalyptus salubris woodland in the Western Australian wheatbelt. I. Arthropods. F. Appl. Ecol. 33, 1281-301.

Beier P. \& Noss R. F. (1998) Do habitat corridors provide connectivity? Conserv. Biol. 12, 1241-52.

Bolger D. T., Alberts A. C., Sauvajot R. M., Potenza P., McCalvin C., Tran D., Mazzoni S., Soule M. E. (1997) Response of rodents to habitat fragmentation in coastal southern California. Ecol. Applic. 7, 552-63.

Brown G. W. (2001) The influence of habitat disturbance on reptiles in a box-ironbark eucalypt forest of southeastern Australia. Biodivers. Conserv. 10, 161-76.

Brown G. W. \& Nelson J. L. (1993) Influence of successional stage of Eucalyptus regnans (mountain ash) on habitat use by reptiles in the central highlands, Victoria. Aust. F. Ecol. 18, 405-17.

Burgman M. A. \& Lindenmayer D. (1998) Conservation Biology for the Australian Environment. Surrey Beatty, Sydney.

Burkey T. V. (1995) Extinction rates in archipelagos - implications for populations in fragmented habitats. Conserv. Biol. 9, 527-41.

Clarke M. J. \& Forsyth S. M. (2000) Hobart 1: 25 000. Department of Primary Industries, Water and Environment, Hobart.

Collinge S. K. (1996) Ecological consequences of habitat fragmentation: implications for landscape architecture and planning. Landscape Urban. Plann. 36, 59-77.
Debinski D. M. \& Holt R. D. (2000) A survey and overview of habitat fragmentation experiments. Conserv. Biol. 14, $342-55$.

Dickman C. R. (1987) Habitat fragmentation and vertebrate species richness in an urban environment. F. Appl. Ecol. 24, 337-51.

Driscoll D. A. (2004) Extinction and outbreaks accompany fragmentation of a reptile community. Ecol. Appl. 14, $220-40$.

Flather C. H. \& Bevers M. (2002) Patchy reaction-diffusion and population abundance: the relative importance of habitat amount and arrangement. Am. Nat. 159, 40-56.

Hadden S. A. \& Westbrooke M. E. (1996) Habitat relationships of the herpetofauna of remnant Buloke woodlands of the Wimmera Plains, Victoria. Wildl. Res. 23, 363-72.

Hanski I. \& Simberloff D. (1996) The metapopulation approach, its history, conceptual domain and application to conservation. In: Metapopulation Biology; Ecology, Genetics and Evolution (eds I. Hanski \& M. E. Gilpin), pp. 5-26. Academic Press, San Diego.

Hogg A. \& Kirkpatrick J. B. (1974) The phytosociology and synecology of some Southern Tasmanian eucalypt forests and woodlands. F. Biogeogr. 1, 227-45.

How R. A. (1998) Long-term sampling of a herpetofaunal assemblage on an isolated urban bushland remnant, Bold Park, Perth. F. R. Soc. WA 81, 143-8.

How R. A. \& Dell J. (2000) Ground vertebrate fauna of Perth's vegetation remnants: impact of 170 years of urbanization. Pac. Conserv. Biol. 6, 198-217.

Hutchinson M., Swain R., Driessen M. (2001) Snakes and Lizards of Tasmania. Nature Conservation Branch, Hobart.

Jackson W. D. (1999) The Tasmanian environment. In: Vegetation of Tasmania (eds J. B. Reid, R. S. Hill, M. J. Brown \& M. J. Hovenden), pp. 11-38. Australian Biological Resources Study, Hobart.

Kellman M. (1996) Redefining roles - plant community reorganization and species preservation in fragmented systems. Glob. Ecol. Biogeogr. Lett. 5, 111-6.

Kirkpatrick J. B. \& Marks F. (1985) Observations on drought damage to some native plant species in eucalypt forests and woodlands near Hobart Tasmania Australia. Pap. Proc. Roy. Soc. Tas. 119, 15-22.

Kitchener D. J., Chapman A., Dell J., Muir B. G., Palmer M. (1980) Lizard assemblages and reserve size and structure in the Western Australian wheatbelt - some implications for conservation. Biol. Conserv. 17, 25-62.

Kitchener D. J. \& How R. A. (1982) Lizard species in small mainland habitat isolates and islands off southwestern Western Australia. Aust. Wildl. Res. 9, 352-63.

Knight R. L., Wallace G. N., Riebsame W. E. (1995) Ranching the view - subdivisions versus agriculture. Conserv. Biol. 9 , 459-61.

Laurance W. F. (2000) Do edge effects occur over large spatial scales? Trends Ecol. Evol. 15, 134-5.

Leaman G. E. (1972) Hobart 1: 50 000. Lands Department Hobart, Hobart.

MacNally R. \& Brown G. W. (2001) Reptiles and habitat fragmentation in the box-ironbark forests of central Victoria, Australia: predictions, compositional change and faunal nestedness. Oecologia 128, 116-25.

Melville J. \& Swain R. (1999) Habitat associations and natural history of the Tasmanian 'snow skinks' (Niveoscincus spp.). Pap. Proc. Roy. Soc. Tas. 133, 57-64.

Minchin P. R. (1987) An evaluation of the relative robustness of techniques for ecological ordination. Vegetatio $\mathbf{6 9}, 89-107$. 
Minchin P. (1990) DECODA: Database for Ecological Community Data. Australian. National University, Canberra.

Mueller-Dombois D. \& Ellenberg H. (1974) Aims and Methods of Vegetation Ecology. Wiley, New York.

Nicholls A. O. (1989) How to make biological surveys go further with generalised linear models. Biol. Conserv. 50, 51-75.

Nunez M. (1983) Estimation of solar radiation received on slopes in Tasmania. In: Proceedings of the Royal Society of Tasmania (eds M. B. Banks \& S. J. Smith), pp. 153-9. Government Press, Hobart.

O'Shea E. M. \& Kirkpatrick J. B. (2000) The impact of suburbanisation on remnant coastal vegetation in Hobart, Tasmania. Appl. Veg. Sci. 3, 243-52.

Rawlinson P. A. (1974) Biogeography and ecology of the reptiles of Tasmania and the Bass Strait area. In: Biogeography and Ecology in Tasmania (ed. W. D. Williams), pp. 291-334. Dr W. Junk, The Hague.

Redburn K. (1999) Life history and habitat of the Tussock Skink, Pseudemoia Pagenstecheri in Tasmania. Honours Thesis. University of Tasmania, Hobart, Tasmania.

Sarre S. (1995) Size and structure of populations of Oedura reticulata (Gekkonidae) in woodland remnants: implications for the future regional distribution of a currently common species. Aust. Ecol. 20, 288-98.

Schneider M. (2001) Habitat loss, fragmentation and predator impact: spatial implications for prey conservation. F. Appl. Ecol. 38, 720 .

Smith G. T., Arnold G. W., Sarre S., Abensperg Traun M., Steven D. E. (1996) The effect of habitat fragmentation and livestock grazing on animal communities in remnants of gimlet Eucalyptus salubris woodland in the Western Australian Wheatbelt. II. Lizards. F. Appl. Ecol. 33, 1302-10.

Sokal R. R. \& Rohlf F. R. (1995) Biometry: the Principles and Practice of Statistics in Biological Research, 3rd edn. Freeman, New York.

Soule M. E., Alberts A. C., Bolger D. T. (1992) The effects of habitat fragmentation on chaparral plants and vertebrates. Oikos 63, 39-47.

Stow A. J., Sunnucks P., Briscoe D. A., Gardner M. G. (2001) The impact of habitat fragmentation on dispersal of cunningham's skink (Egernia cunninghami): evidence from allelic and genotypic analyses of microsatellites. Mol. Ecol. 10, 867-78.

Taylor J. E. \& Fox B. J. (2001) Disturbance effects from fire and mining produce different lizard communities in eastern Australian forests. Austral Ecol. 26, 193-204.

Theobald D. M., Gosnell H., Riebsame W. E. (1996) Land use and landscape change in the Colorado Mountains. 2. A case study of the East River Valley. Mt. Res. Dev. 16, 407-18.

Turner I. M. (1996) Species loss in fragments of tropical rainforest - a review of the evidence. F. Appl. Ecol. 33, 200-9.

Wahren C. H., Williams R. J., Papst W. A. (1999) Alpine and subalpine wetland vegetation on the Bogong High Plains, southeastern Australia. Aust. F. Bot. 47, 165-88.

Wilcox B. A. \& Murphy D. D. (1985) Conservation strategy: the effects of fragmentation on extinction. Am. Nat. 125, 879-87. 